\title{
LOS TEATROS EN EL CHILE ÍNTIMO DEL SIGLO XX. UNA APROXIMACIÓN SOCIOLÓGICA DESDE UNA HISTORIA LOCAL
}

\author{
THEATRES IN THE INTIMATE CHILE OF THE 20TH CENTURY. \\ A SOCIOLOGICAL APPROACH FROM A LOCAL HISTORY
}

\section{MARIO POBLETE VÁSQUEZ JORGE SAAVEDRA UTMAN"}

\section{RESUMEN}

Los teatros en América Latina han tenido un protagonismo central en el desarrollo de las artes, de la cultura y de la sociedad, y el caso de Chile no es la excepción. Si bien el auge de estos espacios ocurre desde mediados del siglo XIX, es desde comienzos del siglo XX cuando se comienzan a extender por todo el país, teniendo su ocaso hacia los últimos 30 años del siglo. Así, se analiza esta realidad a partir del desarrollo de los teatros en Melipilla - una ciudad de rango medio prototípica de la zona central de Chile-, estudiados en tanto lugares de apreciación y creación artística: eje de la industria cultural, requisito de urbanidad, y espacio de socialización. A través de este pueblo-ciudad se reconstruye el trayecto histórico de sus teatros, lográndose establecer las causas profundas de su desaparición como espacios para las artes y el encuentro social. La tesis principal indica que, más allá de las causas exógenas relacionadas con amplios procesos de cambio social a nivel mundial o nacional, fueron causas endógenas, como la falta de apropiación ciudadana de estos espacios, la gestión puramente empresarial de los teatros, y su excesiva rigidez para adecuarse a las nuevas demandas de la actividad artística, las que explican la raíz de su ocaso y posterior desaparición.

Palabras clave: Cultura local, teatros, microhistoria, vínculo social, Chile.

* D.E.A. (Máster) en Ciencias Políticas, Universidad Complutense de Madrid. Investigador de la Biblioteca del Congreso Nacional. Departamento de Estudios. Santiago-Valparaíso, Chile. Correo electrónico: marioeduardo.poblete@gmail.com

** Magíster en Comunicación Política, Universidad de Chile. Candidato a Doctor en 'Media and Communications', Goldsmiths College, Universidad de Londres. Londres, Reino Unido. Correo electrónico: j.saavedra@gold.ac.uk 


\section{ABSTRACT}

Theatres in Latin America have always been actors in the development of arts, culture, and society, and Chile is not the exception. Although the rise of theatres occurred in the middle of the 19th century, it is from the early 20th that they started to be spread through the whole country, while their decline occurred in the last quarter of this century. In this research, we assess the development of theatres and their different dimensions in Melipilla -a prototypical midrange city located in the central Chile- and reconstruct the historical path and disappearance of theatres on its social aspects. The main thesis suggests that, beyond exogenous factors -those relating to ample processes of social change at the global or national scale-, were endogenous causes, such as the lack of citizen empowerment, the managerial-centered administration of theatres and the increasing rigidity of their management, which explain the roots of their decline and later disappearance.

Keywords: Local culture, theatres, microhistory, social tie, Chile.

Recibido: 09.09.14. Aceptado: 18.05.15.

L

OS TEATROS TUVIERON un protagonismo central en el desarrollo cultural de Chile y jugaron un rol relevante en la conformación de sus principales ciudades y centros mineros, desde el siglo XIX hasta el XX, cuando su construcción se expandió más allá de las grandes urbes, convirtiéndose en ejes de la vida social y cultural de ciudades intermedias y pueblos. Fue también hacia el final de este siglo cuando los teatros entraron en un declive permanente, que terminó con ellos cerrados o entregados a usos alejados de su origen, gatillando así el reclamo por la falta de espacios para las artes y/o por la ruina a la que fueron llevados. En consecuencia, la pregunta que guía esta investigación es: ¿por qué desaparecieron los teatros, tras años de permanente actividad y presencia? Para ello se analiza la microhistoria de Melipilla, un pueblo-ciudad de la zona central de Chile, que reúne características similares a las de muchos pueblos del Chile central, como su tamaño intermedio -más que un villorrio, pero menos que una urbe central por esos años-, ambivalencia urbano-rural e industria eminentemente agrícola.

El presente artículo está basado, por una parte, en una investigación bibliográfica sobre la evolución de los teatros en Chile, de las disciplinas artísticas y de los cambios políticos, culturales, sociales y económicos en el país desde fines del siglo XIX (Poblete y Saavedra, 2012). Por otro lado, se sustenta en una reconstrucción histórica a través de narrativas de micro sucesos que permiten detallar e ilustrar aquella serie de hechos que se vinculan causalmente y que permiten explicar aquella desaparición (Falleti y Lynch, 
2009), de forma de lograr una vinculación más precisa entre variables en procesos de causalidad compleja (Falleti, 2006). Esto se realizó a través de la revisión de cada edición de los periódicos que existieron en Melipilla desde 1890 hasta $1990^{1} \mathrm{y}$ entrevistas en profundidad a personas que participaron en el desarrollo de los teatros, desde administradores hasta usuarios. A partir de estos registros se reconocen prácticas - de y en torno a los teatros- y sentidos puestos por quienes se vincularon con ellos, permitiendo a través de un enfoque hermenéutico (Gadamer, 1999; Ricoeur, 2006) responder la pregunta de investigación planteada.

\section{LOS COMIENZOS DE LOS TEATROS EN CHILE}

Los teatros en Chile comenzaron a construirse desde la primera mitad del siglo XIX como una respuesta de la sociedad chilena a la anhelada 'mayoría de edad' del país y a la efectiva popularidad de óperas, operetas y presentaciones teatrales (Piña, 2009, p. 39) que, en tiempos en que los soportes tecnológicos estaban aún ausentes, sustentaban su difusión con la puesta en escena (González y Rolle, 2005, p. 292)2. En sus inicios estos fueron los principales consumos culturales por parte de la 'plutocracia finisecular' de ese entonces (Subercaseaux, 1997a, p. 332). En consecuencia, los teatros nacieron por y para un acceso elitista, lo cual en parte se puede atribuir a la mayor presencia poblacional en las zonas rurales que en las urbanas; y la diferenciación entre una clase alta y letrada, heredera de la nobleza española y opuesta a una numerosa clase baja de trabajadores, labradores y empleados (Piña, 2009, pp. 38-39). Así pues, en su especificidad y devenir histórico, los teatros son comprendidos desde cuatro dimensiones: a) espacios de apreciación y creación artística; b) requisito de urbanidad moderna; c) eje de la industria artístico-cultural; y d) espacio de socialización ${ }^{3}$. La primera de

\footnotetext{
${ }^{1}$ Para una lista completa de los periódicos véase el siguiente enlace: http://mariopoblete. cl/2015/05/04/anexos-los-teatros-en-el-chile-intimo-del-siglo-xx-una-aproximacion-sociologica-desde-una-historia-local-articulo/

${ }^{2}$ Labor que a su vez se vio potenciada por la fuga del músico eclesiástico a escenarios laicos (Claro, 1979; Izquierdo, 2011).

${ }^{3}$ El concepto de socialización es entendido acá según la formulación clásica de Simmel. La socialización es un proceso que está en la base de la distinción entre 'contenido' y 'forma' de la existencia social, siendo particularmente la 'forma' concreta que adquieren los vínculos sociales. Por contraparte, el contenido para Simmel es la individualidad misma, estos son los impulsos, los propósitos, los contenidos e intereses individuales, que no son sociales, sino individuales, que motivan las formas sociales, que modelan, a su vez, las formas específicas de socialización (Wolff, 1950, pp. 40 y ss.).
} 
estas dimensiones se instaló en Chile desde el siglo XIX. Con el arribo del siglo XX, Santiago llegó especialmente preparado "con unos cuarenta salones de espectáculos, 'baratos y cultos”' (González y Rolle, 2005, p. 293); en tanto en Valparaíso, solamente entre 1907 y 1930, se construyeron 18 recintos $^{4}$. Fueron los teatros los hegemonizadores de la apreciación artística $^{5}$ tras el paso desde los salones familiares a los espacios teatrales y de la diversificación de estos, al dejar lentamente de ser exclusivos privilegios de las aristocracias locales. Asimismo, durante el último cuarto del siglo XIX, el teatro también se convirtió en un espacio para la creación (Piña, 2009), pues progresivamente se comenzaron a escribir obras y formar compañías que florecieron a partir de los principales espectáculos sobre tablas chilenas: la zarzuela y los sainetes. Los teatros se tornaron también espacios necesarios para el desarrollo mismo de compañías teatrales. Si antes eran utilizados solamente para los montajes de elencos extranjeros o nacionales, a poco andar se convirtieron en lugar para ensayos y en una necesidad para las compañías locales y sus comunidades, particularmente en ciudades intermedias, que interesadas en las artes escénicas formaban pequeñas agrupaciones al alero de organizaciones sindicales, ateneos y escuelas.

En las principales ciudades se construyeron teatros. Éstos se convirtieron en un requisito de progreso (Collier y Sater, 2004, p. 98) propio de las grandes urbes coloniales americanas (Hardoy y Aranovich, 1983). Fue así como las plazas de armas en Chile contemplaron entre sus principales edificaciones, junto con el edificio de la administración, el templo católico, el almacén, uno o tal vez más restaurantes y posadas, el mercado y el teatro (Benavides et al., 1998).

Gracias a esta incipiente proliferación, los teatros se convirtieron en el contenedor visual de los fenómenos culturales del mundo, lo cual significó una conexión con lo que acontecía fuera de los horizontes del país, en términos de insumos culturales, patrones a imitar y ventana a otras expresiones artísticas. De la mano de la irrupción del cine, los teatros acrecentaron su estatus de espectáculo popular y se convirtieron en uno de los epicentros de disputa por la hegemonía de las narraciones, por el intento de normar lo que se podía ver y no $\operatorname{ver}^{6}$ (Subercaseaux, 1997b) en el marco de una pugna

\footnotetext{
${ }^{4} \mathrm{Al}$ respecto revísese el sitio web Memoria Matinee. Disponible en: http://www.memoriamatinee.com Recuperado el 3 de mayo de 2015.

${ }^{5}$ Aunque, tal como afirman González y Rolle (2005, pp. 274 y ss, 301-306), también lo serán por el circo y por el kiosco de la plaza pública donde emergían y se desarrollaban las bandas.

${ }^{6}$ En este sentido, Subercaseaux (1997b, p. 80) menciona la Liga de las Damas Chilenas, "institución que veía en la cultura moderna (sobre todo en el teatro y en el cine, pero también en el hecho de que la mujer ampliara sus horizontes más allá de la casa y la familia) una amenaza para la moral y para la buenas costumbres".
} 
entre una alta y baja cultura, y entre las estéticas europeas y la búsqueda de una propia. Estas disputas provocaron, por ejemplo, el nacimiento de una dramaturgia ácrata y obrera $(\mathrm{Grez}, 2011)$ y posteriormente un teatro universitario que se oponía al 'pintoresquismo insustancial' (Durán, 1963, p. 168) ligado a la comedia de circunstancias o amorosas (Pradenas, 2006), derivados de la imitación y adaptación de zarzuelas, sainetes y juguetes cómicos.

En cuanto espacio de socialización, los teatros fueron un elemento central de la vida social, en tanto eran lugar 'para ver' y 'dejarse ver', tanto en aquellas presentaciones para la alta sociedad como en recintos más modestos. Allí se enmarcan viejas costumbres propias de la plaza pública, donde la aristocracia asistente al Teatro Municipal de Santiago (Cánepa, 1976; Hurtado, 2011) reproducía un comportamiento establecido para ser vistos y admirados (Núñez, 2010). Asimismo, los teatros de la aristocracia y su obsesión por la ópera fueron símbolos de la representación y expresión de una identidad que perseguía y veneraba lo potencialmente europeo, para con ello lograr una diferenciación de lo criollo-popular no sólo en la escena, sino que también en las butacas. En general, a través de los teatros se buscó instaurar un tipo de comportamiento del público que, sin embargo, sería subvertido por prácticas cotidianas alejadas del anhelo de la élite.

\section{LOS TEATROS EN MELIPILLA DURANTE EL SIGLO XX}

Melipilla, fundada en 1742, está ubicada en el seno de un valle del mismo nombre, 74 kilómetros al sur oeste de Santiago de Chile. Para el año 1907, en su radio urbano, tenía una población aproximada de 6 mil personas ${ }^{7}$ repartidas entre ciudad y campo, donde lo urbano estaba circunscrito a menos de 10 hectáreas. Su principal avenida era Vicuña Mackenna, ya que en ella estaba la estación de trenes, que por esos años tenía conexión a Santiago. Todo lo que estaba fuera de ese perímetro correspondía a caseríos, chacras y grandes haciendas donde los campos mostraban cultivos de cereales y el verde de una fisonomía plagada de vegetación, canales y esteros. A pesar de que hoy esas dimensiones se puedan considerar pequeñas, Melipilla era cabeza del Departamento del mismo nombre y pertenecían a su

\footnotetext{
${ }^{7}$ Comisión Central del Censo. Memoria: presentada al Supremo gobierno por la Comisión del Censo, Santiago de Chile, 1908.
} 
jurisdicción las zonas de Culiprán, Loica, El Monte, Alhué, San Antonio y Curacaví. Con el pasar de los años Melipilla creció paulatinamente en población, servicios e industrias, pero conservó su carácter provinciano, su vida lenta al alero del clima mediterráneo y sus entretenciones pueblerinas. Fue una ciudad-pueblo cuyas dinámicas sociales resultan recurrentes en la zona central (Berdegué et al., 2010; PNUD, 2008).

Los primeros proto-teatros en surgir fueron pequeñas salas acondicionadas por iniciativa privada para actos particulares, a fines de la década de 1890, pero la apertura del primer teatro melipillano ocurre en 1910, con el Teatro Apolo. Subsiguientemente, surgen varios más hasta que se inaugura el Teatro Serrano en 1933, hegemonizando la actividad artística y el desarrollo cultural por casi cuarenta años. El fin de esta trayectoria se encuentra aparejado a la edificación del Cine Palace, espacio de grandes dimensiones que tiene una corta vida, siendo la década de 1980 la de su declive. Todos fueron de propiedad privada, salvo el Serrano, cuya propiedad fue adquirida por el municipio en 1935.

El anterior panorama permite definir períodos para el análisis de determinada secuencia histórica. Utilizando un criterio endógeno en la selección de las etapas históricas (Bartolini, 1999), se reconocen tres períodos. El primero está relacionado con toda la actividad ocurrida previa al Teatro Serrano, desde 1910 hasta 1933. El segundo período se sostiene gracias a la hegemonía propia del Serrano, que tuvo su período de primacía desde 1933 hasta 1968, año en que se inaugura el Cine Palace. Luego se identifica un tercer período, donde si bien aún existe el Serrano en un primer momento, el Palace se convierte en el referente de la ciudad, especialmente en el fin de la década del sesenta e inicio de los setenta, para luego decaer a fines de los ochenta.

\section{LOS TEATROS DE LAS PRIMERAS DÉCADAS: 1910-1933}

El primer período de la vida de los teatros en Melipilla durante el siglo XX comprende desde principios de siglo XX hasta 1933 e incluye la existencia de los teatros Apolo (1910-1911), Melipilla (1911), Alhambra (19191920), Colón (1921-1925) y Esmeralda (1925-1933). Este número obedeció al gran interés que existía entre la clase dirigente local por contar con un teatro, pues consideraban a este tipo de recinto como "esponente de la civilización de un pueblo o mejor dicho el metro con que se mide la intelec- 
tualidad de gobernantes i gobernados" (La Patria, 29 de agosto de 1918) ${ }^{8}$, y por parte de empresarios de la entretención. Los primeros anhelaban un teatro porque "dada la población de la ciudad i el grado de cultura en que se encuentra, es esto de una necesidad absoluta" (La Patria, 29 de agosto de 1918); y los segundos reconocían en esta localidad, con conexión ferroviaria a la capital, un lugar donde el cinematógrafo lograba cautivar a las audiencias $^{9}$ y donde el boxeo y esporádicas compañías teatrales demostraban que podía tener éxito. Por ende, una zona donde era posible obtener dinero administrando un teatro.

En la balanza del éxito fueron los segundos quienes obtuvieron más réditos con la existencia de los teatros, ya que no sólo ganaron dinero gracias a la exhibición de cintas, sino que además lo hicieron con veladas de boxeo y el cultivo de buenas relaciones con las dirigencias municipales, que solamente exigían a cambio el pago de patentes y alguna función a beneficio. No obstante, el obrar de los administradores y el mismo devenir de los teatros, a poco andar, provocó la molestia de la élite local, conservadora y católica -muy similar a la clase alta capitalina por esos años-, por tres razones. Primero, porque esta clamaba 'subir el nivel' de lo que se exhibía, levantando la voz ante cintas consideradas ofensivas a la moral como el filme el 'Triunfo de Venus' ${ }^{10}$. Luego, porque el anhelo de tener orquestas, grandes compañías de teatro y óperas, en un marco de refinación social, nunca se logró. Y en tercer lugar, debido a que los teatros en Melipilla no fueron pomposos arquitectónicamente y tuvieron una concurrencia socioeconómica diversa, dado su bajo costo y ser una entretención diferente a lo existente. Esta desilusión de la élite se manifestó en el primer teatro, el Apolo. Allí se congregaban centenas de personas de diversa procedencia y con un comportamiento que no permitía a todos presenciar plenamente la función. Ciertos sectores de la comunidad, entonces, solicitaron confeccionar una platea donde quienes pagaran más estuvieran al resguardo de aquella otredad bullanguera.

\footnotetext{
${ }^{8}$ Las palabras fueron pronunciadas por el regidor Vicente Segundo Elgueta en sesión municipal, las que fueron reproducidas por el periódico La Patria de Melipilla.

${ }^{9}$ Desde 1907 se encuentran registros en la prensa local que dan cuenta de las permanentes visitas de comerciantes, quienes acudían con una máquina proyectora y cintas que se exhibían con gran expectación entre la población, siendo permanentemente el momento cúlmine de celebraciones organizadas por el municipio.

${ }^{10}$ Se describe más adelante en el artículo.
} 
Como consecuencia, la intención de la autoridad local de construir un teatro municipal con diseño colonial, refinado y donde las diferencias entre públicos estuvieran incorporadas en la construcción, aumentaban. Pero el municipio no tuvo dinero para ello y fueron empresarios los que dieron vida a los teatros Melipilla, Colón, Alhambra, Apolo y Esmeralda. Vida que no estuvo exenta de problemas internos, como ganancias menores a las esperadas, robo de equipos y falta de cintas que exhibir, debido a la caída en la producción fílmica a causa de la Primera Guerra Mundial (Bakker, 2008, p. 227). A pesar de las dificultades, este primer período (1900-1933) culminó con el cierre del Teatro Esmeralda por una razón distinta a las hasta acá señaladas: por la aparición de un competidor ubicado en plena Plaza de Armas -todos los anteriores se habían ubicado en calles adyacentes.

\section{LA CONSTRUCCIÓN DE UN HÁBITO POR EL TEATRO: 1933-1968}

El Teatro Serrano fue inaugurado en 1933 y cerró sus dependencias a fines de la década de 1970. El edificio se levantó en la Plaza de Armas de Melipilla, a raíz de una iniciativa privada de la familia española De la Presa, asentada en Melipilla. Con su compañía, Presa Hermanos, erigieron un recinto para 445 personas bajo estándares de calidad iguales a los de sus pares santiaguinos: con foyer, platea, galería, escenario, camarines y comercio adyacente. Durante los dos primeros años, su administración corrió por cuenta de los dueños, quienes vendieron posteriormente el recinto al municipio en una suma menor a la del valor comercial de la época.

Con el teatro largamente soñado, el municipio concesionó permanentemente el recinto a privados para su administración. Dicho sistema funcionó con diversos problemas y una muestra fue que de once administraciones, diez tuvieron problemas contractuales. Así y todo, el Teatro Serrano desde un inicio fue la principal entretención para la población al constituir un punto de encuentro, diversión e información. Fue también un espacio para el cine, para presentaciones teatrales de compañías santiaguinas, festivales de música con exponentes locales y manifestaciones de la cultura popular, como la visita de boxeadores famosos, cantantes nacionales e internacionales y compañías de radioteatro. Fue un espacio donde lo popular se daba cita, frustrando nuevamente a la élite local que, tal como en el primer período, anhelaba un lugar de mayor refinación, llevándola a plantear iniciativas de poca proyección, como el Círculo de Divulgación Cultural, que en 1943 invitaba a veladas "de un carácter casi familiar (...) en salas de casas 


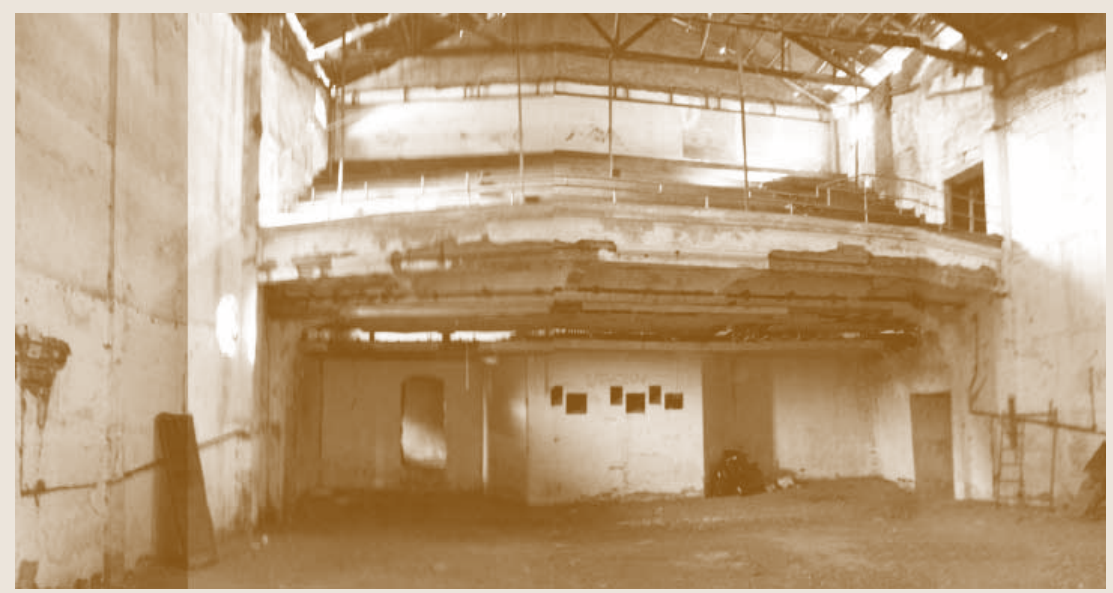

Ruinas del antiguo Teatro Serrano de Melipilla, antes de su demolición en 2013.

particulares y de preferencia los domingos a las 6 de la tarde" (El Labrador, 17 de marzo de 1943). Otras iniciativas, como la de un grupo de vecinos de la élite local, que en 1946, junto al municipio, desarrollaron encuentros de música docta, tampoco perduraron ${ }^{11}$.

En cambio, el resto de la comunidad daba un uso permanente al Teatro Serrano en su condición de espectadores, convirtiendo al recinto en un centro cultural donde "se hacían beneficios, se hacían sketches, se traían compañías de Santiago, se hacía la velada bufa, que era algo muy impresionante", en opinión del actor Ramón Núñez ${ }^{12}$, un niño para la década de 1950. En menor medida se usaba para el trabajo de incipientes compañías locales, las que en ocasiones tenían la posibilidad de presentar en el teatro alguna de sus funciones. "El Teatro Serrano no siempre estaba dispuesto, porque tenían contrato para pasar películas y no podíamos ensayar ahí. Solamente se podía hacer un ensayo general, los ensayos previos los hacía-

${ }^{11}$ Esta iniciativa consistió en un ciclo de tres conciertos en 1946. El primero se desarrolló en el Teatro Serrano y no tuvo cobro de entrada. Como el público que llegó fue poco y hubo ciertos comportamientos no deseados por los organizadores, el segundo se hizo en un salón municipal. El tercero volvió a realizarse en el salón municipal, pero se cobró por asistir, limitando de esta forma el libre acceso a la comunidad.

${ }^{12}$ Ramón Núñez Villarroel (1941) es un destacado actor, director teatral y académico chileno. Nacido en Melipilla, se formó profesionalmente en la Universidad Católica y posteriormente en el London Drama Centre de Reino Unido. En 2010 recibió el Premio Nacional de Arte, mención teatro. 
mos en la Escuela 1 por la gracia del director de esa época", sostenía el actor Archibaldo Larenas ${ }^{13}$. De todas formas, el Teatro Serrano fue un problema para el municipio, que quiso venderlo a inicios de los sesenta, sin éxito, y luego decidió continuar con su concesión, cayendo en manos de empresarios que lo explotaron desde la perspectiva lucrativa, pero no así poniendo atención a su conservación, a su adecuación a los tiempos o de su uso más allá de los habituales filmes.

\section{DEL AUGE A LA CAÍDA: 1968-1990}

Con una gran popularidad de los teatros y su uso como salas de cine y de conciertos, en los años 60, Melipilla vio levantar otro teatro al que se llamó Cine Palace dado su preeminente uso como cinematógrafo. Sin un escenario del todo apto para las artes escénicas, contaba con una capacidad para 1.300 personas en una ciudad por ese entonces de 40 mil habitantes. El dueño del recinto, el empresario de origen árabe José Massoud, invirtió también en una radio en Amplitud Modulada, alojando todo en un mismo edificio. De esta forma, unió cine, música e información a través de una plataforma que le permitió disfrutar, entre 1968 y 1973, de un éxito en boleterías. Durante esta etapa, dicho recinto se caracterizó por los estrenos de cine del momento, por sus rotativas de cine mexicano, por la continuación del concurso 'Buscando la Mejor Voz' ${ }^{14}$ y por conciertos de populares músicos de la época como Libertad Lamarque ${ }^{15}$ y Dean Reed ${ }^{16}$, siendo habitual que las butacas estuvieran permanentemente ocupadas. Sin embargo, el 11 de septiembre de 1973 el golpe de estado que derrocó al Presidente Allende

\footnotetext{
${ }^{13}$ Archibaldo Larenas fue profesor de la Escuela Industrial de Melipilla, en el mismo período en que estudiaba en el Teatro Experimental (Univ. de Chile). Fue un importante impulsor del teatro en Melipilla en los años 50, a través de un taller que dependía del Ateneo Juan Francisco González, instancia dedicada al cultivo de las artes en la comunidad. Luego desarrollaría una importante carrera teatral y fílmica en el país.

${ }^{14}$ De este concurso emergieron algunos músicos que, posteriormente, desarrollaron una prolongada y exitosa carrera, como el conjunto folclórico de crítica social Quelentaro y el conjunto de rancheras Hermanos Bustos.

${ }^{15}$ Libertad Lamarque (1908-2000) fue una actriz y cantante argentina que hizo la mayor parte de su carrera en México. Filmó más de 50 películas y grabó más de 400 canciones. Su trabajo cinematográfico y musical la elevó a la categoría de primera estrella del cine y la canción latinoamericana.

${ }^{16}$ Dean Reed (1938-1986) fue un cantante estadounidense de rock and roll con mediano éxito en EE.UU. y mejor suerte en América Latina. Su adscripción a causas políticas de izquierda y posterior residencia en la República Democrática Alemana le granjearon el apodo de “Elvis Rojo".
} 
dio paso al 'apagón cultural' ${ }^{17}$, a la persecución de la disidencia y a un clima de miedo producto de desapariciones y asesinatos perpetrados por los órganos represores.

Tras estos sucesos, el Palace entró en un declive paulatino, ya que entre 1974 y 1979 siguió exhibiendo filmes y presentando conciertos con relativo éxito. Curiosamente, esta fue la época en que más teatro se presentó en Melipilla, producto de la iniciativa de Eduardo Mallea, un profesor local con particular entusiasmo por las artes escénicas, que halló en el dueño del Palace un aliado. Mas este envión no prosiguió en los ochenta, años en que el Palace continuó con una programación de filmes, pero con una caída en las audiencias. Las escasas funciones teatrales, por su parte, se trasladaron hacia gimnasios y el negocio dejó de ser el éxito de años anteriores. La década siguiente nació con la esperanza de un renacer cultural producto del fin de la dictadura. Sin embargo, los 90 se caracterizaron por la falta de espacios de entretención y para las artes, por lo que funciones de teatro y danza se realizaron en gimnasios, escuelas y galpones de manera esporádica. No hubo en los años de recuperación democrática una política pública en pos de un espacio para las artes, transitando la hegemonía desde los antiguos lugares públicos de encuentro y reunión hacia los centros comerciales y malls.

\section{LAS RAZONES DEL DECLIVE}

De esta investigación eminentemente microhistórica (Tilly, 1984, pp. 8186), sustentada en el desarrollo de narrativas de sucesos encadenados causalmente, se desprenden las diversas causas más genéricas respecto del declive y desaparición de los teatros en Melipilla, pudiéndose clasificar analíticamente en factores endógenos y exógenos. Los endógenos son tres y tienen que ver con las propias dinámicas internas de la comunidad melipillana y de los teatros locales; en tanto que los exógenos hacen referencia a los amplios procesos de cambio social, que a su vez se entrecruzan con los primeros.

La primera de las causas endógenas tiene relación con la administración de los teatros. Las salas de teatro durante todo el siglo XX fueron concebi-

\footnotetext{
${ }^{17}$ Las razones eran diversas y contundentes: permanente prohibición a la libertad de expresión, cierre de estudios de cine y escuelas audiovisuales, vetos, censuras a publicaciones y discos, abolición de leyes en apoyo a las artes, exilio a artistas, quema de recintos culturales, saqueo de museos y bibliotecas, cierre de medios de comunicación y control total de lo que escribía la prensa escrita que se mantenía en pie (Mouesca, 1992; Zegers, 1999; Jordán, 2009; Errázuriz, 2009; entre otros).
} 
das y comprendidas como una empresa para generar dinero. Incluso durante la existencia del Teatro Serrano, la lógica de concesionar el recinto a un administrador privado, por parte de la Municipalidad, se adecuó a la noción de que el teatro debía dar réditos económicos para propietarios y administradores. La mayoría de los fracasos en las administraciones se vincularon precisamente con ello, salvo por contados casos que tuvieron que ver con factores colaterales relacionados con la Segunda Guerra Mundial ${ }^{18}$ o delictivos ${ }^{19}$. Así, esta noción del arte y las actividades culturales como un negocio lucrativo, permaneció durante todo el siglo, fracasando en el largo plazo tanto en Melipilla como probablemente hubiera ocurrido en muchas partes del país, si no es por la existencia de un régimen intensivo de donaciones $^{20}$. Como añadido perverso, la comuna nunca tuvo una política cultural en todo el siglo XX que asentara en sus espacios teatrales un quehacer coordinado desde el uso y la apreciación artística cultural destinada a contribuir al aumento del capital social y al bienestar social de la población ${ }^{21}$. El único requisito que en la práctica el municipio exigió a los administradores fue complementar el negocio, esporádicamente, con ciertos usos por parte del municipio u otra organización para realizar espectáculos. El hecho de que el Teatro Serrano fuera literalmente cerrado a fines de los setenta habla de cómo fueron concebidos estos espacios: si no generaban dinero, no servían.

Un segundo factor endógeno es el grado de apropiación ciudadana de los recintos. En Melipilla, la relación entre el teatro y la población fue la de

\footnotetext{
${ }^{18}$ Con esto nos referimos a un caso particular que afectó al empresario italiano Víctor Francione, quien en 1941 debió abandonar la administración del Serrano, como consecuencia de la acción de la embajada de Estados Unidos, que persiguió a ciudadanos e inmigrantes procedentes de países enemigos de los EE.UU. durante la Segunda Guerra Mundial. Italia era uno de ellos y Francione había declarado su adscripción al régimen fascista de Benito Mussolini. Por lo tanto, la embajada presionó al municipio y este, a su vez, al empresario para que diera fin a sus funciones, como consigna el periódico El Labrador del 22 de enero de 1941.

${ }^{19}$ En este caso, consignamos el término de la administración Selman-Varcellino, a cargo del Serrano entre los años 1943 y 1949, cuando uno de los socios huyó del país tras descubrirse que los cheques entregados para adelantar el pago por la concesión del recinto no tenían fondos. Durante algunos meses la administración del teatro estuvo abandonada hasta la llegada de un nuevo empresario.

${ }^{20}$ Por mencionar un caso, el propio Teatro Municipal de Santiago, para mantener una cartelera y una actividad pujante, recibió financiamiento en los primeros años del 2000 de parte del Estado, mediante el Consejo Nacional para la Cultura y las Artes, también de la propia Municipalidad de Santiago, de las municipalidades de Las Condes, Vitacura y Providencia y de la empresa privada.

${ }^{21}$ En este sentido, Ateca (2009) realiza un estudio que entiende al capital social como determinante del consumo cultural; por otro lado Guetzkow (2002) realiza un repaso de los estudios que entienden que el arte y la cultura tienen un impacto en las comunidades.
} 
'espectáculo-espectador' y, como se mencionó más arriba, el acento estuvo puesto en los réditos económicos que el teatro generaba. Por lo tanto, la actividad artística no propició la relación 'centro cultural-ciudadanía cultural' o 'espacio para las artes-desarrollo de agrupaciones locales'. En consecuencia, no existió una contundente participación artística de la ciudadanía en la organización, promoción y desarrollo de alguna disciplina, o incluso en su misma administración, que permitiera una apropiación efectiva y significativa de dichos espacios sociales. En la medida en que sí se hubiera dado dicha apropiación ciudadana, el cierre de estos recintos hubiera encontrado más obstáculos.

Un tercer elemento endógeno que contribuyó al declive fue la pérdida de la preponderancia de los teatros en tanto espacios multiuso. Solo servían para el cine, en tanto su uso para el teatro y la música se veía muy limitado. La histórica rigidez y excesiva univocidad de las salas en Melipilla, pensadas desde una óptica de negocio cortoplacista y preponderantemente fílmico, jugó finalmente en su contra.

Los tres factores anteriormente señalados explican parcialmente el declive y cierre de los teatros, pues ciertos factores exógenos potenciaron las dinámicas autodestructivas internas de los teatros como espacio social. Estos factores exógneos son dos amplios procesos de cambio social: la dictadura militar comenzada en 1973 y el desarrollo tecnológico de otros soportes de apreciación artística.

El primero de estos procesos, y que nace a partir del golpe de estado de 1973 es un hito no solo político, sino también social y cultural, que condiciona la vida del país y de Melipilla. En términos generales, desarticula los vínculos sociales, persigue políticamente determinadas expresiones artísticas, crea un clima de desconfianza y miedo a exponerse públicamente, estableciendo políticas restrictivas de la expresión e imponiendo un tipo de arte y cultura oficiales (Errázuriz, 2009). Así y todo, en Melipilla se pudo observar que durante los primeros años de la dictadura hubo una gran cantidad de actividades artísticas, en su mayoría espectáculos venidos desde fuera de la ciudad y cada vez con menor participación de la ciudadanía, dejando notar un primer aspecto en el declive de la actividad social en torno a los teatros. En los años ochenta se volvió más oscura la situación y la actividad en torno a los teatros cayó considerablemente, facilitada en gran medida por el terremoto que afectó la zona central de Chile en 1985. Por otro lado, el arte y la cultura oficial fueron promocionados desde los ápices jerárquicos de la dictadura, los cuales eran diametralmente diferentes, tanto en su gestación como en su desarrollo, con los espectáculos que florecían 
desde la comunidad en décadas anteriores. Finalmente, el modelo económico neoliberal impuesto estableció y exacerbó la lógica costo-ganancia -primer factor endógeno-, no considerando la inversión en cultura como inversión social. Todo esto contribuyó a que, en los últimos 20 años del siglo, los teatros cayeran en desgracia: se cerró el Serrano y el Palace quedó moribundo. El primero se arrendó como bodega y el segundo se convirtió en una discoteca.

Un segundo proceso sobreviene con el desarrollo tecnológico. Sin duda, la masificación de la televisión contribuyó en una primera etapa al declive de los teatros y otro tanto lo hizo la aparición del VHS. Estos soportes promovieron la apreciación artística de manera más simple y accesible ${ }^{22}$, brindando una satisfacción relativamente similar, pero con atractivos nuevos, como la comodidad de la casa, la cercanía familiar y el ahorro en un entorno privado. La masificación de estos soportes tecnológicos no fue un hecho trivial para el caso melipillano, ya que la preponderancia que tuvo el cine en la vida de los teatros circunscribió la pugna al ámbito fílmico. Y en esa reyerta el gran perdedor fue el Palace, dado que nunca diversificó su oferta en el largo plazo y se ciñó a una cartelera eminentemente cinematográfica. Aparejado al proceso de innovación tecnológica mencionado, se produjo en Chile un declive en las tradicionales salas de cine, problema al que el Estado hizo frente mediante el arriendo de salas de cine en todo el país a través de la empresa estatal Chile Films, cuestión que duró hasta su privatización en 1988. En los noventas, los cines tradicionales sufrieron un revés con el desembarco de empresas extranjeras, las que llegaron a ocupar el $70 \%$ del mercado nacional ${ }^{23}$.

\section{A MODO DE CONCLUSIÓN: EL DETERIORO DEL VÍNCULO SOCIAL}

El vínculo social es entendido como la instancia en que "las voluntades humanas se hallan entre sí en múltiples relaciones, cada una de ellas es una acción recíproca que, en cuanto hecha o dada por un lado, es sufrida o recibida por los demás" (Tönnies, 1927, p. 298), y en que dicha reciprocidad se presenta, a su vez, de forma aproblemática para los integrantes de la comunidad (Schutz, 1977, p. 128). En Melipilla es posible observar su

\footnotetext{
${ }^{22}$ No había que salir del hogar, o solo para arrendar los casetes de VHS.

${ }^{23}$ Como Cinemark, Hoyts y Showcase. Al respecto revísese el sitio web Memoria Chilena. Disponible en: http://www.memoriachilena.cl/temas/index.asp?id_ut=lasalasdecineenchi le(1896-2000). Recuperado el 3 de mayo de 2015.
} 
deterioro en aquellos desencuentros sufridos por la comunidad dentro del espacio social que fue el teatro. En este sentido, una fractura la representó el ya mencionado 'Triunfo de Venus' ${ }^{24}$. Era el año 1921, época en que el Teatro Colón era administrado por Juan Vizcaya, quien se enfrentó al sacerdote Ramón Merino a propósito de la reproducción de la cinta que incluía desnudos y que el párroco melipillano buscó prohibir por sobre todas las cosas. Este hecho marcó el principio de una serie de sucesos similares, en que se produciría el enfrentamiento entre dos cosmovisiones contrapuestas, la de católicos ultramontanos frente a otra más bien liberal, que tendieron a fracturar la élite chilena, y que en el ámbito político, a nivel nacional, ya había explotado en 1857 con la denominada Cuestión del Sacristán ${ }^{25}$, pero que en Melipilla recién emerge en el siglo XX.

Una segunda fractura se gestó antes de la ético-religiosa y tuvo que ver con el eje élite-pueblo -o cuestión social- que se plasmó de diversas maneras. Una de ellas se evidenció en la arquitectura de los teatros, "ya sea como la separación que implementó el Teatro Apolo entre platea y galería hacia 1911, como con la separación ya consagrada que tenía el Serrano entre platea y paraíso, un espacio para los más pudientes el primero, y el otro para los estratos bajos" (Saavedra y Poblete, 2012, p. 278). Sin embargo, y a pesar de la división de públicos en los teatros, la irrupción del pueblo no pudo ser contenida por las normas y divisiones establecidas. La aparición de lo popular fue avasalladora. Así, el sujeto popular adquiriría más visibilidad, mientras que los intentos de la élite por diferenciación serían infructuosos, siendo la creación del Círculo de Divulgación Cultural del año 1943 y el de los conciertos de 1946 casos paradigmáticos, por ser evidentes muestras de la lejanía artística, cultural y física que deseaba tener la élite respecto del pueblo. Particular atención convoca lo anterior, porque si bien el clivaje social era innegable en la sociedad externa a los recintos teatrales, el que fuera llevado al seno de los teatros indica un debilitamiento considerable del sentido de comunidad en Melipilla. Sin embargo, no surgió en Melipilla un arte crítico que representara la cada vez más acentuada diferencia social, sino hasta el surgimiento del grupo Quelentaro en los años 60, quienes fue-

${ }^{24}$ Que es, a nuestro juicio, una particular manifestación del clivaje clerical-anticlerical muy documentado a nivel nacional (Scully, 1992, p. 35).

${ }^{25}$ La Cuestión del Sacristán remite a una pugna de poder entre Iglesia Católica y el Poder Ejecutivo iniciada en 1856, a raíz de una sanción disciplinaria por parte de la jerarquía católica chilena contra un sacristán que luego fue revertida por la justicia civil, desatando una crisis entre Iglesia y Estado, junto a un quiebre definitivo al interior del Partido Conservador. 
ron unos de los pioneros en evidenciar, desde la creación e interpretación, las marcadas diferencias sociales.

A pesar de que ambos clivajes dañaron el sentido unívoco de comunidad, convirtiendo al teatro en un espacio social más diverso, éste no desapareció. El denominado 'desmantelamiento social' del teatro ocurrió durante las décadas de 1980, en plena dictadura, y de 1990, la primera de la democracia posdictatorial, que no alteró sustancialmente las bases profundas del plan de censura cultural sostenido por los militares. A partir de 1990, en la comuna de Melipilla no hubo diálogo ni una participación social sustancial en pos de un espacio cultural de encuentro, ni tampoco se construyó un teatro público o un centro cultural (Saavedra y Poblete, 2012). Así, los años que transcurren desde 1990 a 2000 se asemejan a los de comienzos del siglo $\mathrm{XX}$ al ser los dos únicos períodos en que la ciudad careció de un recinto teatral que funcionara y tuviera una programación continua. Ambos, no obstante, están marcados por un gran sismo devastador y llevan aparejados una promesa: el anhelo de un teatro.

\section{REFERENCIAS}

Ateca, V. (2009). "El capital humano como determinante del consumo cultural". Estudios de Economía Aplicada, 27(1), 87-110.

Bakker, G. (2008). Entertainment Industrialised. The Emergence of the International Film Industry, 1890-1940. London: Cambridge.

Bartolini, S. (1999). "Tiempo e investigación comparativa”. En La comparación en las ciencias sociales. Madrid: Alianza.

Benavides, J.; Pizzi, M.; Valenzuela, M. (1998). Ciudades y arquitectura portuaria: Los puertos mayores del litoral chileno. Santiago, Chile: Editorial Universitaria.

Berdegué, J.; Jara, E.; Modrego, F.; Sanclemente, X. y Schejtman, A. (2010). Comunas rurales de Chile. Documento de Trabajo 60. Programa Dinámicas Territoriales Rurales. Santiago de Chile: Rimisp.

Cánepa, M. (1976). La ópera en Chile. Santiago, Chile: Editorial del Pacífico.

Claro, S. (1979). "Música catedralicia en Santiago durante el siglo pasado". Revista Musical Chilena, 42(148), 7-36.

Collier, S. and Sater, W. (2004). A History of Chile, 1808-2002. New York: Cambridge.

Durán, J. (1963). "El teatro chileno moderno". Anales de la Universidad de Chile, $126,168-203$.

Errázuriz, L. (2009). “Dictadura militar en Chile, antecedentes del golpe estético cultural”. Latin American Research Review 44(2), 136-157.

Falleti, T. (2006). "Theory-guided process-tracing in comparative politics: so- 
mething old, something new". Newsletter of the Organized Section in Comparative Politics of the American Political Science Association, 17(1), 9-14.

Falleti, T., y Lynch, J. (2009). "Context and Causal Mechanisms in Political Analysis”. Comparative Political Studies, 42(9), 1143-1166.

Gadamer, H.-G. (1999). Verdad y método, vol. I, octava edición. Salamanca: Ediciones Sígueme.

González, J. y Rolle, C. (2005). Historia social de la música popular en Chile, 1890-1950. Santiago de Chile: Ediciones Universidad Católica de Chile.

Grez, S. (2011). ¿Teatro ácrata o teatro obrero? Chile, 1895-1927. Estudios Avanzados, 23. En http://www.revistaidea.usach.cl/ojs/index.php/ideas/article/view/162

Guetzkow, J. (2002). How the Arts Impact Communities: An introduction to the literature on arts impact studies. New Jersey: Center for Arts and Cultural Policies Studies, Princeton.

Hardoy, J. y Aranovich, C. (1983). "Escalas y funciones urbanas de la América Española hacia 1600. Un ensayo metodológico”. En De Solano, F. (coord.), Estudios sobre la ciudad Iberoamericana. Madrid: Consejo Superior de Investigaciones Científicas.

Hurtado, M. (2011). Dramaturgia chilena 1890-1990: autorías, textualidades, historicidad. Santiago, Chile: Frontera Sur.

Izquierdo, J. (2011). El Órgano Flight \& Son de la Catedral de Santiago. Tesis para optar al Grado de Magíster en Artes, mención Musicología, Universidad de Chile.

Jordán, L. (2009). "Música y clandestinidad en dictadura: la represión, la circulación de músicas de resistencia y el casete clandestino". Revista Musical Chilena, 212, 77-102.

Mouesca, J. (1992). Cine chileno: veinte años: 1970-1990. Santiago, Chile: Mineduc.

Núñez, L. (2010). "La aceptación de la diversidad cultural o el difícil arte de escuchar”. En La construcción cultural de Chile. Valparaíso: Consejo Nacional de la Cultura y las Artes.

Piña, J. (2009). Historia del teatro en Chile 1890-1940. Santiago, Chile: RIL Editores.

Pradenas, L. (2006). Teatro en Chile. Huellas y trayectorias. Santiago, Chile: Lom.

Programa de las Naciones Unidas para el Desarrollo (2008). Desarrollo Humano en Chile Rural. Santiago de Chile: PNUD.

Ricoeur, P. (2006). La teoría de la interpretación. Discurso y excedente de sentido, sexta edición, México: Siglo XXI Editores.

Saavedra, J. y Poblete, M. (2012). Historia social de los teatros en Chile: Melipilla en el Siglo XX. Santiago, Chile: Chancacazo.

Schutz, A. (1977). Las estructuras del mundo de la vida. Buenos Aires: Amorrortu Editores. 
Scully, T. (1992). Los partidos de centro y la evolución política chilena. Santiago, Chile: CIEPLAN, University of Notre Dame.

Subercaseaux, B. (1997a). Historia de las ideas y de la cultura en Chile. Tomo I. Sociedad y cultura liberal en el siglo XIX: J. V. Lastarria. Santiago, Chile: Editorial Universitaria.

Subercaseaux, B. (1997b). Historia de las ideas y de la cultura en Chile. Tomo II. Fin de siglo: La época de Balmaceda. Santiago, Chile: Editorial Universitaria.

Tilly, C. (1984). Grandes estructuras, procesos amplios, comparaciones enormes. Madrid: Alianza.

Tönnies, F. (1927). Comunidad y sociedad. Buenos Aires: Losada.

Wolff, K. (1950). The Sociology of George Simmel. Glencoe: Free Press.

Zegers, M. (1999). 25 años de teatro en Chile. Santiago, Chile: Departamento de Programas Culturales de la División de Cultura del Ministerio de Educación. 